\title{
PRODUÇÃO E QUALIDADE DE FOLHAS DE AMOREIRA EM FUNÇÃO DA ÉPOCA DO ANO E DE COLHEITA
}

\author{
José Ednilson Miranda ${ }^{1 *}$; Gisele Aparecida Bonacin²; Roque Takahashi ${ }^{3}$ \\ ${ }^{1}$ Depto. de Fitossanidade - UNESP/FCAV, Via de Acesso Prof. Paulo Donato Castellane, km 5 - CEP: $14884-900$ - \\ Jaboticabal, SP. \\ ${ }^{2}$ Pós-Graduanda em Agronomia, Área de Concentração em Produção Vegetal - UNESP/FCAV. \\ ${ }^{3}$ Depto. de Zootecnia - UNESP/FCAV. \\ *Autor correspondente <joseemiranda@ig.com.br>
}

RESUMO: A quantidade e qualidade das folhas de amoreira (Morus alba L.) exercem influência marcante sobre o desenvolvimento do bicho-da-seda e são, por sua vez, influenciadas por fatores como a idade das folhas, época do ano e características genéticas dos cultivares. Avaliou-se a produção e a qualidade nutricional de folhas de cinco cultivares de amoreira em diferentes épocas do ano e de colheita, objetivando verificar sua adaptação na região de Jaboticabal (SP). As folhas dos cultivares 'Miura', 'Korin', 'Calabresa', 'FM86' e 'FM Shima-Miura' foram colhidas na primavera, verão e outono após 45, 60, 75 e 90 dias da poda (DAP) e avaliadas quanto à produção de folhas níveis de proteína bruta (PB) e fibra em detergente neutro (FDN). As melhores produções foram verificadas em 'FM Shima-Miura', principalmente aos 75 DAP na primavera e no verão e aos 90 DAP no outono. No verão, as colheitas efetuadas aos 60, 75 e 90 DAP resultaram em produções mais elevadas. As épocas de colheita que resultaram em maiores níveis de PB foram aos 45 e 60 DAP e em menores níveis de FDN aos 60 DAP, respectivamente. Foi possível conciliar altos níveis de PB, baixos níveis de FDN e relativamente alta produção de massa foliar somente na colheita efetuada aos 75 DAP.

Palavras-chave: Morus alba, bicho-da-seda, sericicultura, massa foliar, proteína bruta

\section{LEAF PRODUCTION AND QUALITY OF MULBERRY IN RELATION TO SEASON AND HARVEST TIME}

\begin{abstract}
The amount and quality of mulberry (Morus alba L.) leaves have remarkable influence on the development of the silkworm and they are, therefore, influenced by factors as the age of the leaves, season and genetic characters of the cultivar. The production and the nutritional quality of leaves of five mulberry cultivars were evaluated under different seasons of the year and harvest times, having in view the indication of cultivars for the area of Jaboticabal, SP, Brazil. Leaves of cultivars 'Miura', 'Korin', 'Calabresa', 'FM86' and 'FM Shima-Miura' were harvested in spring, summer and autumn, 45, 60, 75 and 90 days after pruning (DAP) and evaluated through leaf mass production, crude protein (CP) and neutral detergent fiber (NDF). Best productions were verified in 'FM Shima-Miura', mainly at 75 DAP for spring and summer and at 90 DAP for autumn. For summer, the harvest made at 60,75 and 90 DAP resulted in highest productions. Harvest times that resulted in largest CP levels were 45 and 60 DAP and in smallest NDF level was 60 DAP, respectively. It was possible to reunite high PB levels, low NDF levels and relatively high leaf mass productions only at the harvest time of 75 DAP.
\end{abstract}

Key words: Morus alba, silkworm, sericulture, leaf mass, crude protein

\section{INTRODUÇÃO}

A amoreira, utilizada na alimentação do bichoda-seda, é perene, bastante rústica e possui vida útil de cerca de 20 anos. Suas plantas são de fácil cultivo e de excelente desenvolvimento, mesmo em períodos de estiagens prolongadas. No Estado de São Paulo, a fase vegetativa da amoreira ocorre entre meados de agosto e maio (Tinoco \& Almeida, 1992), produzindo, em média, $4 \mathrm{~kg}$ de folhas planta ${ }^{-1}$, em três colheitas anuais (Hanada \& Watanabe, 1986). Com um teor protéico de aproximadamente $20 \%$ na massa seca, a planta se constitui em alternativa como importante forrageira para a alimentação de animais. A quantidade e qualidade das folhas produzidas pelos cultivares de amoreira são de suma importância no crescimento das lagartas de bichoda-seda, refletindo diretamente na produtividade e na constituição físico-química do fio de seda produzido pelos insetos (Juliatto, 1985; Tinoco \& Almeida, 1992). Daí a importância da escolha do cultivar de amoreira a ser plantado.

$\mathrm{Na}$ escolha do melhor material a ser cultivado dois aspectos devem ser considerados: a produção de folhas e sua qualidade nutricional. No entanto, variações são freqüentes nos teores de nutrientes encontrados nas folhas, as quais podem ser influenciadas por diversos fatores, como a época do ano (com diferentes condições climáticas), a idade da folha (Campos et al., 1980; Takahashi, 1996), a variedade de amoreira (Fonseca et al., 1987) e os tipos de poda (Satoh et al., 1977). 
A faixa mais adequada de temperatura para o crescimento da amoreira é de 24 a $28^{\circ} \mathrm{C}$. A precipitação pluvial variando de 600 a $2500 \mathrm{~mm}$, regularmente distribuída por todas as estações de crescimento, favorece o desenvolvimento da amoreira (Fonseca \& Fonseca, 1986).

As proteínas e as fibras brutas são constituintes bioquímicos que influenciam o valor nutritivo das folhas dos vegetais. A proteína através de seus aminoácidos tem papel fundamental nos processos metabólicos, sendo limitantes para o crescimento de insetos (Scriber \& Slansky Jr., 1981). O fornecimento de folhas ao bichoda-seda com altos níveis de proteína e baixos teores em fibra proporciona melhor desenvolvimento das larvas e maior produção de casulos de seda (Ito \& Kobayashi, 1978; Ullal \& Narasimhanna, 1987; Li \& Sang, 1984). Cerca de $70 \%$ da proteína do fio de seda, produzido pelo bicho-da-seda, provém da folha de amoreira (Hanada \& Watanabe, 1986). O nível de fibra em detergente neutro (FDN) está relacionado com a capacidade de digestão, sendo que baixos níveis de FDN nas folhas de amoreira proporcionam às lagartas do bicho-da-seda uma maior digestibilidade do alimento. Desta forma, folhas com altos níveis de proteína bruta (PB) e baixos níveis de FDN são mais adequadas para a alimentação dos insetos.

Objetivou-se neste trabalho avaliar a produção e a qualidade foliar de cinco cultivares de amoreira na região de Jaboticabal - SP, em quatro épocas de colheita, durante as estações de crescimento primavera, verão e outono.

\section{MATERIAL E MÉTODOS}

O presente trabalho foi realizado no setor de Sericicultura da FCAV/UNESP, Jaboticabal - SP (575 m de altitude, latitude de $21^{\circ} 15^{\prime} 22^{\prime \prime} S$, Iongitude $48^{\circ} 18^{\prime} 58^{\prime \prime}$ )). O solo onde se encontra o amoreiral é do

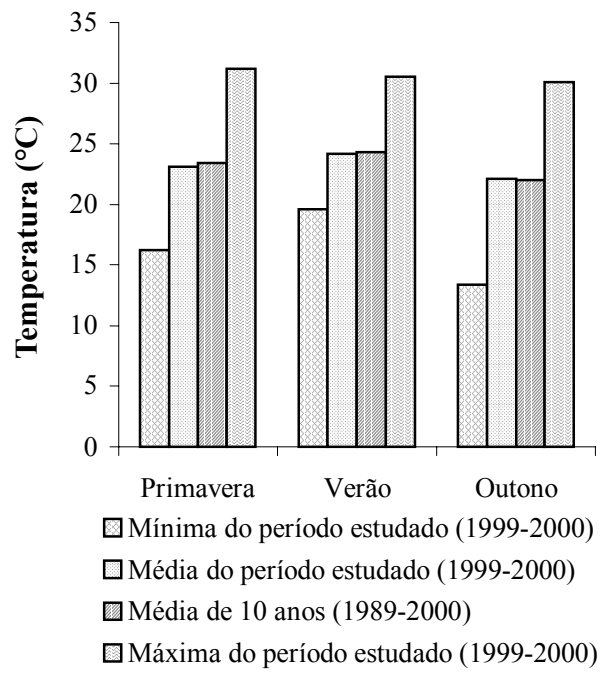

tipo Latossolo Vermelho-Escuro eutrófico, A moderado, textura argilosa, relevo suave ondulado. A análise química de solo revelou os seguintes valores: $\mathrm{pH}\left(\mathrm{CaCl}_{2}\right)$ $-5,5 ; \mathrm{P}-8 \mathrm{mg} \mathrm{dm}^{-3} ; \mathrm{K}-3,1 \mathrm{mmol}_{\mathrm{c}} \mathrm{dm}^{-3} ; \mathrm{Ca}-12 \mathrm{mmol}_{\mathrm{c}}$ $\mathrm{dm}^{-3} ; \mathrm{Mg}-5,0 \mathrm{mmol}_{\mathrm{c}} \mathrm{dm}^{-3} ; \mathrm{CTC}-66,1 ; \mathrm{V}-45 \%$. Os elementos meteorológicos, utilizados neste trabalho (Figura 1), foram extraídos de um conjunto de dados pertencentes ao acervo da área de Agrometeorologia do Departamento de Ciências Exatas da FCAV/UNESP.

As plantas das amoreiras, 'Miura', 'Korin', 'Calabresa', 'FM86' e 'FM Shima-Miura'), com doze anos e plantadas em espaçamento de $3,0 \times 0,6 \mathrm{~m}$, receberam manejos culturais baseados nas recomendações técnicas de Takahashi (1996), inclusive a poda em cepo.

Foram amostrdas três plantas por cultivar, escolhidas ao acaso e completamente colhidas com cortes rente ao solo, com três repetições.

As podas iniciais foram sempre efetuadas no início das estações primavera, verão e outono e as colheitas aos 45, 60, 75 e 90 dias após a poda (DAP). Imediatamente após cada colheita, somente as folhas, (limbo e pecíolo) eram pesadas ainda frescas, em balança eletrônica. A produção de massa foliar foi avaliada com base na massa fresca de folhas. Para a obtenção dos teores de proteína bruta (PB) e fibra em detergente neutro (FDN), separaram-se três amostras de cada material, as quais foram secadas em estufa a $60^{\circ} \mathrm{C}$ por 72 horas e, posteriormente, analisadas no Laboratório de Nutrição Animal da FCAV/UNESP, conforme metodologia sugerida por Silva (1988).

Análise estatística foi efetuada para produção de massa foliar, utilizando-se o Delineamento Inteiramente Casualizado em esquema de parcelas sub-subdivididas no tempo com três repetições, sendo os cultivares considerados como parcelas, as estações de crescimento como subparcelas e as épocas de colheita como sub-subparcelas, através do Procedimento GLM

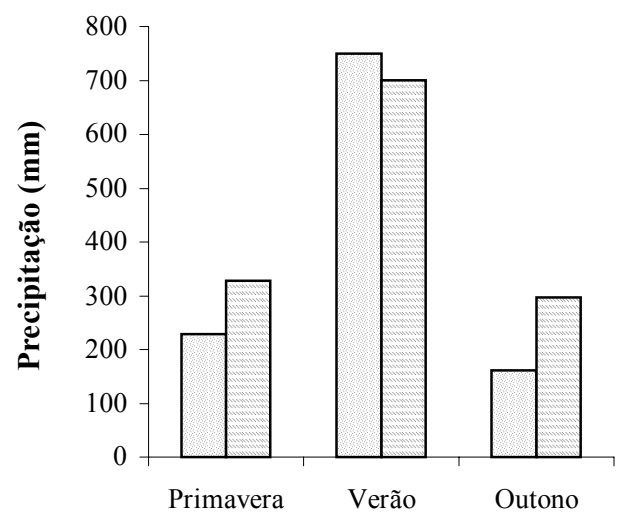

$\square$ Período estudado (1999-2000)

$\square$ Média de 10 anos (1989-2000)

Figura 1 - Dados de temperaturas e precipitação pluvial das três estações de crescimento da amoreira. Jaboticabal, setembro/1989 a maio/ 2000. 
(SAS, 1996). As médias foram comparadas pelo teste de Tukey $(P<0,05)$. Para a avaliação dos níveis de PB e FDN foram utilizadas estatísticas descritivas.

\section{RESULTADOS}

\section{Produção de massa foliar das amoreiras}

Na primavera, a máxima produção de folhas foi registrada para o cultivar 'FM Shima-Miura', aos 75 DAP, a qual foi superior $(P<0,05)$ às produções nas demais épocas de colheita (Tabela 1). 'Calabresa' apresentou aos 75 e 90 DAP, produções de folhas que não diferiram entre si $(P>0,05)$, mas foram superiores $(P<0,05)$ às verificadas aos 45 e 60 DAP. O mesmo comportamento foi verificado com 'Korin'. O cultivar 'Miura' apresentou sua máxima produção de massa foliar somente aos 90 DAP, a qual foi superior $(P<0,05)$ às produções obtidas nas demais épocas de colheita. Os resultados de 'FM 86 ' foram semelhantes aos observados para 'Miura'. 'FM Shima-Miura' se destacou também por apresentar produções superiores às dos demais cultivares testados $(P<0,05)$ aos 60, 75 e 90 DAP.

No verão, estação de maior precipitação e maiores temperaturas (Figura 1), verificaram-se picos de produção aos 75 DAP para 'FM Shima-Miura'; aos 90 DAP para 'Calabresa'; e aos 75 e 90 DAP, indiferentemente $(P>0,05)$, para 'Miura', 'Korin' e 'FM86'.
Entre os cultivares, novamente 'FM Shima-Miura' apresentou a maior produção aos 75 DAP, superior $(P<0,05)$ às dos demais; aos 90 DAP, sua produção somente não diferiu $(P>0,05)$ da apresentada por 'Miura', tendo sido superior $(P<0,05)$ às dos demais cultivares.

No outono, as colheitas aos 75 e 90 DAP não diferiram entre si $(P>0,05)$ em cada cultivar, exceto 'Calabresa', cuja colheita aos 90 DAP resultou em produção superior $(P<0,05)$ à obtida aos 75 DAP. Produções mais elevadas de 'FM Shima-Miura' em relação aos demais cultivares também foram registradas nesta estação, sendo que em todas as épocas de colheita 'FM Shima-Miura" apresentou produções superiores $(P<0,05)$ à dos demais cultivares. De maneira geral, a produção de massa foliar no outono ficou aquém das obtidas nas outras duas estações, provavelmente tendo sido influenciada pelo baixo volume de chuvas da estação (Figura 1), que comprometeu o desenvolvimento das plantas.

Para se avaliarem os efeitos da interação entre as estações de crescimento e a época de colheita, utilizaram-se médias obtidas com todos os cultivares agrupados, desconsiderando-se assim o efeito genotípico (Tabela 2).

No verão, aos 75 e 90 DAP, ocorreram produções foliares superiores $(P<0,05)$ às verificadas no outono, nas respectivas épocas de colheita. As

Tabela 1 - Produção de massa foliar (massa fresca) de cinco cultivares de amoreira, durante as três estações de crescimento, aos 45, 60, 75 e 90 dias após a poda.

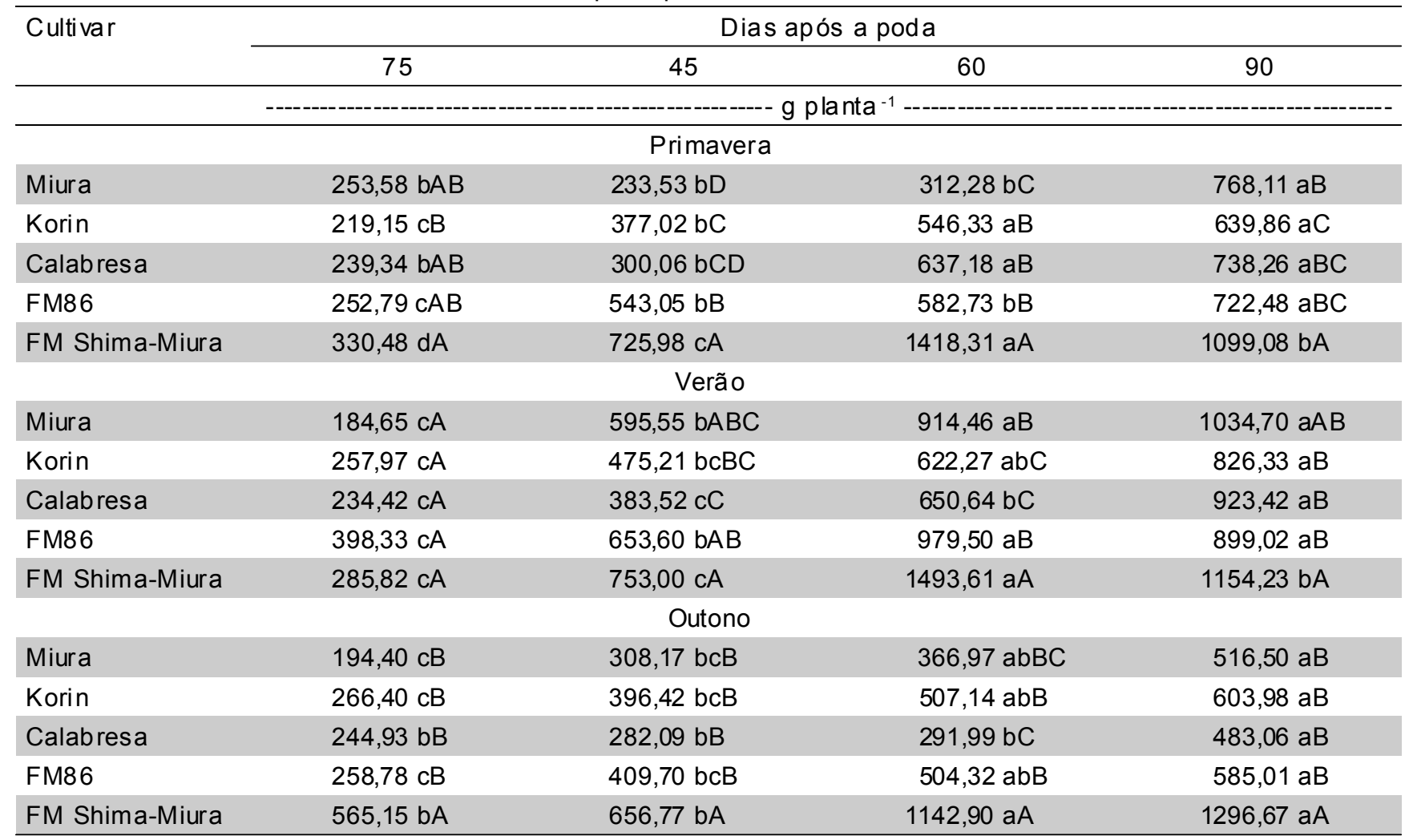

Letras maiúsculas iguais na mesma coluna e letras minúsculas iguais na mesma linha mostram não haver diferença entre os tratamentos correspondentes, com base no teste de Tukey $(P>0,05)$. 
produções foliares ocorridas na primavera não diferiram $(P>0,05)$ das ocorridas no verão e no outono em nenhuma das épocas de colheita. Nas três estações, as colheitas a 75 e 90 DAP resultaram em produções superiores $(P<0,05)$ às colheitas a 45 e 60 DAP.

Através da utilização das médias obtidas com o agrupamento das diferentes épocas de colheita, avaliouse os efeitos da interação entre os cultivares e as estações de crescimento (Tabela 3), desconsiderandose assim o efeito da idade das folhas no momento da colheita.

O cultivar 'Miura' apresentou maior produção de massa foliar no verão, sendo superior $(P<0,05)$ à do outono. Suas produções de massa foliar não diferiram $(P>0,05)$ das apresentadas pelos cultivares 'Korin', 'Calabresa' e 'FM 86' nas três estações. No entanto, 'Miura' apresentou produções de massa foliar inferiores $(P<0,05)$ à de 'FM Shima-Miura' na primavera e no outono.

Dentro de cada estação, as produções de massa foliar dos cultivares 'Korin', 'Calabresa' e 'FM 86' não diferiram entre si $(P>0,05)$ nem da verificada em 'Miura'; entretanto, foram inferiores a 'FM Shima-Miura' (Tabela 3).

Nas três estações de crescimento, o cultivar 'FM Shima-Miura' foi o de maior produção de massa foliar, sendo superior $(P<0,05)$ aos demais cultivares na

Tabela 2 - Produção de massa foliar (massa fresca) de cinco cultivares de amoreira, durante as três estações de crescimento, aos 45, 60, 75 e 90 dias após a poda.

\begin{tabular}{|c|c|c|c|}
\hline \multirow{2}{*}{$\begin{array}{l}\text { Época de colheita } \\
\text { (dia após a poda) }\end{array}$} & \multicolumn{3}{|c|}{ Estação do ano } \\
\hline & Primavera & Verão & Outono \\
\hline & \multicolumn{3}{|c|}{ - } \\
\hline 45 & $259,07 \mathrm{aB}$ & $272,24 \mathrm{aC}$ & $305,93 \mathrm{aC}$ \\
\hline 60 & $435,93 \mathrm{aB}$ & $572,18 \mathrm{aB}$ & $410,63 \mathrm{aBC}$ \\
\hline 75 & $699,36 \mathrm{abA}$ & $932,10 \mathrm{aA}$ & $562,67 \mathrm{bAB}$ \\
\hline 90 & $793,56 \mathrm{abA}$ & 967,54 aA & $697,04 \mathrm{bA}$ \\
\hline
\end{tabular}

Letras maiúsculas iguais na mesma coluna e letras minúsculas iguais na mesma linha mostram não haver diferença entre os tratamentos correspondentes, com base no teste de Tukey $(P>0,05)$.

Tabela 3 - Produção de massa foliar (massa fresca) de cinco cultivares de amoreira, durante as três estações de crescimento.

\begin{tabular}{llll}
\hline \multirow{2}{*}{ Cultivar } & \multicolumn{3}{c}{ Estação do ano } \\
\cline { 2 - 4 } & Primavera & \multicolumn{1}{c}{ Verão } & Outono \\
\hline \multirow{2}{*}{ Miura } & 391,88 abB & 682,34 aAB & 346,51 bB \\
Korin & 445,59 aB & 545,45 aB & 443,49 aB \\
Calabresa & 478,71 aB & 548,00 aB & 325,52 aB \\
FM86 & 525,26 aB & 732,61 aB & 439,45 aB \\
FM Shima-Miura & 893,46 aA & 921,67 aA & 915,37 aA \\
\hline
\end{tabular}

Letras maiúsculas iguais na mesma coluna e letras minúsculas iguais na mesma linha mostram não haver diferença entre os tratamentos correspondentes, com base no teste de Tukey $(P>0,05)$. primavera e no outono; no verão, sua produção não diferiu $(P>0,05)$ de 'Miura' e 'FM 86', mas foi superior $(P<0,05)$ à 'Korin' e 'Calabresa' (Tabela 3$)$.

Apesar de produções de massa foliar numericamente mais altas no verão que na primavera e outono terem sido evidenciadas em todos os cultivares, apenas o cultivar 'Miura' reagiu diferenciadamente entre as estações, apresentando produção de verão superior $(\mathrm{P}, 0,05)$ à de outono.

\section{Qualidade nutricional das folhas de amoreira}

As concentrações de proteína bruta $(\mathrm{PB})$ não variaram entre os cultivares (Tabela 4). Colheitas aos 45 e 60 DAP revelaram as concentrações mais elevadas de PB, notando-se quedas aos 75 DAP e, mais acentuadamente, aos 90 DAP. As concentrações de PB tenderam a decrescer com o retardamento da colheita dos cultivares, demonstrando seu decréscimo estar relacionado ao processo de envelhecimento das folhas. Os valores de PB registrados para os cultivares variaram de 23,4 a $27,5 \%$.

As concentrações de fibra em detergente neutro (FDN) não variaram entre os cultivares, oscilando ente 23 e $27 \%$ (Tabela 4). As menores concentrações de FDN foram registrados aos 60 e $75 \mathrm{DAP}$, respectivamente. Os níveis de FDN não sofreram influência marcante da estação nem do genótipo, mas somente do tempo entre a poda e a colheita das folhas.

\section{DISCUSSÃO}

Nos vegetais, a temperatura influencia a regulação do metabolismo e, portanto, o processo de crescimento e desenvolvimento (Herter et al., 1997). Por sua vez, a temperatura interna das plantas é regulada pelos movimentos estomáticos, que envolvem a presença de água. No presente estudo, as condições de temperatura e disponibilidade de água mais favoráveis ao crescimento e à produção de massa foliar de plantas de amoreira ocorreram na estação do verão (Tabela 1 ). Temperaturas raramente excedentes a $30^{\circ} \mathrm{C}$ e disponibilidade de água (Figura 1) parecem ter estimulado a abertura estomática nesta estação, favorecendo o incremento do processo metabólico das plantas de amoreira (conforme sugerido por Reichardt, 1985), tendo este efeito sido significativo aos 75 e 90 DAP. Na primavera, a temperatura média $\left(23,1^{\circ} \mathrm{C}\right)$ foi um pouco inferior à do verão, mas a temperatura máxima $\left(31,2^{\circ} \mathrm{C}\right)$ foi mais elevada (Figura 1). Entretanto, o fator preponderante na produção de massa foliar da amoreira parece ter sido a precipitação pluvial, cujos níveis foram bastante modestos na primavera $(229 \mathrm{~mm})$ e no outono (161 mm), em comparação ao verão $(750 \mathrm{~mm})$ (Figura 1). O baixo volume de chuvas parece ter comprometido o desenvolvimento das plantas, especialmente no outono. Isto ocorre devido à sensibilidade das plantas à falta d'água, a qual varia com o estágio de crescimento, mas é notada em toda a fase vegetativa das plantas 
Tabela 4 - Proteína bruta (PB) e fibra em detergente neutro (FDN) de cinco cultivares de amoreira, durante as três estações de crescimento e aos 45,60 , 75 e 90 dias após a poda.

\begin{tabular}{|c|c|c|}
\hline Parâmetro & PB (\%) & FDN (\%) \\
\hline \multicolumn{3}{|c|}{ Cultivar } \\
\hline Miura & $26,28 \pm 2,38$ & $24,60 \pm 2,57$ \\
\hline Korin & $25,88 \pm 2,62$ & $25,58 \pm 2,35$ \\
\hline Calabresa & $26,05 \pm 2,11$ & $24,48 \pm 1,50$ \\
\hline FM 86 & $25,47 \pm 2,22$ & $24,34 \pm 1,91$ \\
\hline Fm Shima-Miura & $25,33 \pm 2,44$ & $25,63 \pm 2,41$ \\
\hline \multicolumn{3}{|c|}{ Estação de Crescimento } \\
\hline Primavera & $26,84 \pm 2,33$ & $24,86 \pm 3,03$ \\
\hline Verão & $25,86 \pm 1,75$ & $25,20 \pm 1,80$ \\
\hline Outono & $24,70 \pm 2,36$ & $24,73 \pm 1,60$ \\
\hline \multicolumn{3}{|c|}{ Época de Colheita } \\
\hline 45 DAP & $27,16 \pm 1,20$ & $25,75 \pm 1,47$ \\
\hline $60 \mathrm{DAP}$ & $27,49 \pm 1,70$ & $22,89 \pm 1,31$ \\
\hline 75 DAP & $25,13 \pm 2,44$ & $24,45 \pm 1,39$ \\
\hline 90 DAP & $23,43 \pm 0,79$ & $26,75 \pm 2,38$ \\
\hline
\end{tabular}

(Slatyer, 1969). Deficiência hídrica afeta os processos fisiológicos, como fotossíntese (Brakke \& Allen Jr., 1995), ação estomatal, respiração, translocação e partição de assimilados (Begg \& Turner, 1976).

Quanto à concentração de PB no decorrer das estações do ano, na primavera obtiveram-se os níveis mais elevados, superando o verão. Quader et al. (1992) e Sarker et al. (1992) também observaram em amoreira teores de PB mais elevados durante a colheita de primavera, comparativamente à colheitas em outras épocas do ano. A digestibilidade da proteína bruta também é maior na primavera (Petkov \& Mircheva, 1979). É possível que o baixo volume de precipitação pluvial ocorrido no outono tenha reduzido o conteúdo de PB, corroborando os resultados de Singhal \& Roopa (1998), o que pode ser explicado pela aceleração da senescência das folhas e redução da fotossíntese em função da baixa disponibilidade de água para o metabolismo, resultando na menor produção de fotoassimilados (Johnson et al., 1974).

As épocas de colheita que resultaram em maiores níveis de PB foram 45 e 60 DAP, vindo a seguir 75 DAP; os menores níveis de FDN foram verificados aos 60 e 75 DAP, respectivamente. Por outro lado, independentemente do cultivar, 45 e 60 DAP mostraram ser épocas muito precoces para a colheita de folhas, visto que os picos de produção ocorreram sempre aos 75 ou 90 DAP, épocas que parecem indicar um satisfatório tempo disponível à planta para a translocação dos fotoassimilados. As variações entre 75 e 90 DAP se deveram provavelmente ao fator genotípico dos cultivares.
Os cultivares mais utilizados pelos sericicultores no Brasil apresentaram produção de massa foliar inferior à de 'FM Shima-Miura'. 'Miura', o cultivar mais plantado no Estado do Paraná (Miranda et al., 1999), apresentou relativamente alta capacidade fotossintética apenas no verão. Particularmente no outono, uma visível suscetibilidade à menor disponibilidade hídrica ocorrida em comparação com o verão (Figura 1) foi notada neste cultivar, apresentando as folhas da região basal com menor teor de clorofila e senescência adiantada. Takahashi (1996), avaliando a produção anual de alguns cultivares de amoreira, verificou que o cultivar 'Miura' apresentou produção $13 \%$ inferior a 'Korin' e $22 \%$ inferior a 'FM 86'. De fato, uma inferioridade numérica do cultivar 'Miura' em relação a 'Korin' e 'FM 86' nas estações da primavera e do outono também foi observada no presente estudo.

O cultivar 'Calabresa', apesar de ser extensivamente plantado no Estado de São Paulo (Takahashi, 1996), apresentou produção de massa foliar relativamente baixa nas três estações. Campos et al. (1980) verificaram que a produção de folhas de 'Calabresa' foi superada pelas variedades 'Formosa', 'Miura', 'Toshiana' e 'Yamada'. Fonseca et al. (1985; 1986) em estudos de competição entre vários híbridos de amoreira, obtiveram produções de folhas de 'IZ 19/ 13', 'IZ 5' e 'IZ 40' cerca de $100 \%$ maiores que da 'Calabresa', enquanto que ' $I Z 56 / 4$ ' produziu cerca de $200 \%$ mais que aquela variedade.

O cultivar que se destacou em todas as estações de crescimento foi 'FM Shima-Miura', com a maior produção de massa foliar, tendo sua máxima produção sido observada aos 75 DAP nas estações da primavera e verão e aos 90 DAP no outono. O pico de produção de 'FM Shima-Miura' aos 75 DAP denota precocidade fenológica em relação aos demais cultivares. A posterior queda de produção aos 90 DAP pode ter sido reflexo do processo de senescência das folhas da planta. Mesmo com a menor disponibilidade de água verificada no outono, o cultivar 'FM Shima-Miura' apresentou produção superior aos demais em todos as épocas de colheita, demonstrando desta maneira sua maior resistência a estiagens. $O$ alto potencial produtivo de 'FM Shima-Miura' pode estar relacionado ao seu vigor híbrido. 'FM Shima-Miura' é material resultante do cruzamento das variedades 'Shimaguwa' e 'Miura' (Takahashi, 1996). Materiais híbridos têm-se mostrado mais produtivos e de maior qualidade nutricional que variedades "comuns" (Fonseca et al., 1986). O uso de híbridos selecionados é adotado na maioria dos países que exploram a sericicultura, aproveitando-se das vantagens da heterose, que gera genótipos de alta produção e com períodos vegetativos e reprodutivos mais uniformes (Fonseca et al., 1985). As características de 'FM Shima-Miura' quanto à produção de massa foliar, precocidade fenológica e certa resistência à estiagem tornam-no um cultivar promissor, podendo ser uma opção 
interessante para o uso na sericicultura. Estudos adicionais devem ser efetuados com o cultivar, testandose o mesmo sob outras condições climáticas e pedológicas, bem como avaliando-se seu efeito nutricional sobre o bicho-da-seda.

\section{CONCLUSÕES}

As máximas produções de massa foliar de amoreira são verificadas entre 75 e 90 DAP, no verão;

A antecipação da colheita de 90 DAP (momento mais comumente utilizado pelos sericicultores) para 75 DAP é mais vantajosa, especialmente na primavera e no verão, implicando na obtenção de maior produção de massa foliar e com níveis satisfatórios de PB e FDN para a alimentação do bicho-da-seda;

'FM Shima-Miura' destacou-se como o de maior produção de massa foliar, denotando ser um cultivar com alto potencial para o uso na sericicultura.

\section{REFERÊNCIAS BIBLIOGRÁFICAS}

BEGG, J.; TURNER, N. Crop water deficits. Advances in Agronomy, v.28, p.161-207, 1976

BRAKKE, M.; ALLEN JR., L.H. Gas exchange of citrus seedlings at different temperatures, vapor-pressure deficits, and soil water content. Journal of The American Society for Horticultural Science, v.120, p.497-504, 1995.

CAMPOS, A.R.; FONSECA, A.S.; ABRAMIDES, P.; ABREU, O.C.; CAMPOS, B.E. S. de. Competição entre seis variedades de amoreira (Morus alba L. para produção de massa verde. Revista de Agricultura, v.5, p.243-254, 1980.

FONSECA, A.S.; FONSECA, T.C. Cultura da amoreira e criação do bichoda-seda: sericicultura. São Paulo: Livraria Nobel, 1986. 246p.

FONSECA, A.S.; FONSECA, T.C.; PAOLIERI, L. Híbridos naturais de amoreira. Boletim da Indústria Animal, v.42, p.71-77, 1985

FONSECA, A.S.; FONSECA, T.C.; SCHAMMASS, E.A. Competição de híbridos naturais e artificiais de amoreira. Boletim da Indústria Animal, v.43, p.367-373, 1986.

FONSECA, A.S.; FONSECA, T.C.; CUNHA, E.A.; SCHAMMASS, E.A Competição de variedades, híbridos naturais e híbridos artificiais de amoreira - IV. Boletim da Indústria Animal, v.44, p.329-334, 1987.

HANADA, Y.; WATANABE, J.K. Manual de criação do bicho-da-seda. Curitiba: Cocamar, 1986. 224p.

HERTER, F.G.; ZANOL, G.C.; REISSER JR., C. Características ecofisiológicas do pessegueiro e da ameixeira. Informe Agropecuário, v.18, p.19-23, 1997.
ITO, T.; KOBAYASHI, M. Rearing of the silkworm. In: TAZIMA, Y. (Ed.) The silkworm: an important laboratory tool. Tokyo: Kodansha, 1978. cap.4, p.83-102.

JOHNSON, R.R.; FREY, N.M.; MOSS, D.N. Effect of water stress on photosynthesis and transpiration of frag leaves and spikes of barley and wheat. Crop Science, v.14, p.728-731, 1974.

JULIATTO, S.T. Amoreira: híbridos mais produtivos. São Paulo: CATI, 1985. $23 p$.

LI, R.; SANG, O. The relationship between quality of mulberry leaves and some economics characters during the later larval stage. Science of Sericulture, v.10, p.197-201, 1984.

MIRANDA, J.E.; TAKAHASHI, R.; SILVA, A.F. da. Efeito de genótipos de amoreira sobre o desenvolvimento e a produção do bicho-da-seda. Revista de Agricultura, v.74, p.169-177, 1999.

PETKOV, M.; MIRCHEVA, D. Studies on the composition and digestibility of nutrient in leaves of different mulberry varieties in trails with silkworm. 2. Summer and Autumn feeding. Zhivotnov' Dni Nauki, v.16, p.113-117, 1979./ Resumo em Nutrition Abstract Review, v.51, p.437, 1981.

QUADER, M.A.; QAIYYUM, M.A.; SARKER, A.A.; RAB, M.A.; AHMED, S.U. Varietal response to NPK fertilizers in combination with foliar spray of urea on leaf yield and leaf quality of mulberry. Bullettin of Sericulture Research, v.3, p.64-66, 1992.

REICHARDT, K. A água: absorção e translocação. In: FERRI, M.G. (Coord.) Fisiologia vegetal. São Paulo: EPU, 1985. cap.1, p.20-21.

SARKER, A.A.; QUADER, M.A.; RAB, M.A.; AHMED, S.U. Studies on vitamin and amino acid constituents of mulberry leaves. Bullettin of Sericulture Research, v.2, p.103-106, 1992.

SAS - Institute. The SAS System for Windows: release 6.12 Ts Level 0020. Cary, 1989/1996. 1 CD-Rom.

SATOH, M.; KRIEDEMANN, P.E.; LOVEYS, B.R. Changes in photosynthetic activity and related processes following decapitation in mulberry trees. Physiologia Plantarum, v.41, p.203-210, 1977.

SCRIBER, J. M.; SLANSKY JR., F. The nutritional ecology of immature insects. Annual Review of Entomology, v.26, p.183-211, 1981.

SILVA, D.J. Análise de alimentos: métodos químicos e biológicos. 2.ed. Viçosa: UFV, 1988. 165p.

SINGHAL, B.; ROOPA, R. Changes in physiological and biochemical parameters of promissing mulberry (Morus indica L.) under water stress condition. Philippine Journal of Science, v.127, p.277-286, 1998.

SLATYER, R.O. Physiological significance of internal water relations to crop yield. In: EASTIN, J.D. (Ed.) Physiological aspects of crop yield. Madison: ASA, 1969. p.53-83.

TAKAHASHI, R. Características vegetativas e nutricionais de cultivares de amoreira utilizados na alimentação do bicho-da-seda (Bombyx mori L.) (Lepidoptera: Bombycidae). Jaboticabal, 1996. 122p. Tese (LivreDocência) - Faculdade de Ciências Agrárias e Veterinárias, Universidade Estadual Paulista "Júlio de Mesquita Filho".

TINOCO, S.T.J.; ALMEIDA, R.A.C. Manual de sericicultura. Campinas: CATI, 1992. 67p.

ULLAL, S.R.; NARASIMHANNA, M.N. Handbook of practical sericulture. Bangalore: Central Silk Board, 1987. 166p.

$\overline{\text { Recebido em } 02.04 .01}$ 